\title{
Papers
}

\section{Behavioural counselling in general practice for the promotion of healthy behaviour among adults at increased risk of coronary heart disease: randomised trial}

\author{
Andrew Steptoe, Sheelagh Doherty, Elizabeth Rink, Sally Kerry, Tony Kendrick, Sean Hilton
}

\begin{abstract}
Objective To measure the effect of behaviourally oriented counselling in general practice on healthy behaviour and biological risk factors in patients at increased risk of coronary heart disease.

Design Cluster randomised controlled trial. Participants 883 men and women selected for the presence of one or more modifiable risk factors: regular cigarette smoking, high serum cholesterol concentration (6.5-9.0 mmol/l), and high body mass index (25-35) combined with low physical activity. Intervention Brief behavioural counselling, on the basis of the stage of change model, carried out by practice nurses to reduce smoking and dietary fat intake and to increase regular physical activity. Main outcome measures Questionnaire measures of diet, exercise, and smoking habits, and blood pressure, serum total cholesterol concentration, weight, body mass index, and smoking cessation (with biochemical validation) at 4 and 12 months.
\end{abstract}

Results Favourable differences were recorded in the intervention group for dietary fat intake, regular exercise, and cigarettes smoked per day at 4 and 12 months. Systolic blood pressure was reduced to a greater extent in the intervention group at 4 but not at 12 months. No differences were found between groups in changes in total serum cholesterol concentration, weight, body mass index, diastolic pressure, or smoking cessation.

Conclusions Brief behavioural counselling by practice nurses led to improvements in healthy behaviour. More extended counselling to help patients sustain and build on behaviour changes may be required before differences in biological risk factors emerge.

\section{Introduction}

Lifestyle change is central to health promotion and the prevention of coronary heart disease. ${ }^{12}$ Two large trials of coronary heart disease prevention, the family heart and OXCHECK studies, ${ }^{34}$ have been particularly influential in British general practice. Although both showed small but significant effects on risk of coronary heart disease, the results called into question the cost effectiveness of health promotion in the general practice setting. ${ }^{5}$ Neither study concerned either patients at increased risk of coronary heart disease or behaviourally oriented counselling. ${ }^{16}$ Lengthier programmes to alter smoking habits, diet, and physical activity have more substantial effects. ${ }^{7-9}$ Counselling directed at behavioural and attitudinal change may produce greater changes than traditional educational approaches to health promotion, particularly when tailored to the individual's readiness to change. ${ }^{10-12}$ We describe the effects on behaviour and cardiovascular risk factors of behaviourally oriented counselling on the basis of the stage of change model. ${ }^{13}$ This model categorises patients into stages of readiness to change behaviour (from precontemplation through contemplation, preparation, and action, to the maintenance of change), with different types of advice and skill training being appropriate at different stages. The intervention was carried out by practice nurses in patients at increased risk of coronary heart disease. It was hypothesised that compared with control, behavioural counselling would lead to greater reductions in smoking and dietary fat intake and increases in regular physical activity, together with greater reductions in blood pressure, serum total cholesterol concentration, weight, and body mass index.

\section{Participants and methods}

The design of this parallel group randomised trial has been described elsewhere. ${ }^{14}$ Twenty general practices were allocated to intervention and control conditions (see website) using the minimisation technique $\mathrm{e}^{15}$ to balance groups for the Jarman score of social deprivation, ${ }^{16}$ ratio of patient to practice nurse hours per week, and fundholding status (including wave of entry).

Patients were recruited on the basis of one or more modifiable cardiovascular risk factors: regular cigarette smoking (more than one cigarette per day), high serum cholesterol cocentration (6.5-9.0 mmol/l), or combined high body mass index (25-35) and low physical activity (fewer than 12 episodes of vigorous or moderate exercise for at least 20 minutes in the past 4 weeks, according to criteria based on the national fitness survey). ${ }^{17}$ Patients were excluded if they were on active follow up or drugs for coronary heart disease, had had cardiovascular disease or peripheral vascular disease,

\author{
Department of \\ Psychology, \\ St George's \\ Hospital Medical \\ School, London \\ SW17 0RE \\ Andrew Steptoe \\ professor \\ Sheelagh Doherty \\ research fellow \\ Department of \\ General Practice \\ and Primary Care, \\ St George's \\ Hospital Medical \\ School \\ Elizabeth Rink \\ research manager \\ Sally Kerry \\ lecturer in statistics \\ Tony Kendrick \\ reader \\ Sean Hilton \\ professor \\ Correspondence to: \\ A Steptoe \\ asteptoe@sghms. \\ ac.uk
}

BMJ 1999;319:943-8

website

extra

The flow of participants through the trial appears on the BMJ's website

www.bmj.com 
had a serious chronic illness, or were prescribed a special diet or lipid lowering drugs.

The target sample size was 100 patients per practice. Taking intracluster correlations of risk factors into account, we calculated that this would detect a drop in smoking prevalence from $50 \%$ to $41 \%$, and a decrease of $0.27 \mathrm{mmol} / \mathrm{l}$ in total serum cholesterol concentration with $90 \%$ power at the $5 \%$ significance level.

After recruitment and baseline assessment patients were counselled by practice nurses in smoking cessation, dietary fat reduction, and increasing physical exercise as appropriate either using behaviourally oriented methods (intervention group) or their own usual methods, involving information provision and exhortation. Patients were reassessed at 4 and 12 months.

\section{Behavioural counselling}

One practice nurse from each of the 10 intervention practices was trained in behavioural counselling on the basis of the stage of change model. Training was adapted from the Health Education Authority's package Helping People Change. ${ }^{19}{ }^{19}$ Nurses were trained both to assess a patient's readiness to change behaviour and to use attitude change, goal setting, and specific behavioural advice to enable change. Training took place over 3 days, with a retraining and refresher day after 6 months. The goal in the smoking intervention was complete abstinence, and counselling was supported by nicotine replacement therapy when appropriate. ${ }^{20}$ Patients with increased serum cholesterol concentration were counselled to reduce dietary fat intake and to increase fruit and vegetable consumption within the context of a balanced diet, without specifying targets of the proportion of energy derived from fats. Patients with combined increased body mass index and lack of regular physical activity were counselled to increase their activity levels to 12 sessions of moderate or vigorous activity per month.

Patients in the intervention arm of the study were invited for three counselling sessions if they had two risk factors and for two counselling sessions if they had only one risk factor. The order in which risk factors were targeted was determined after negotiation between nurse and patient. Counselling sessions were scheduled to last no more than 20 minutes, and between sessions the nurse contacted the patient by telephone one or two times to consolidate the counselling and to encourage behaviour change.

\section{Assessment measures}

The physical assessment measures were calculation of body weight and body mass index, and total serum cholesterol concentration and blood pressure. Cholesterol was measured in all patients at 12 months, but at 4 months only in those with initially increased concentrations. Smoking status was assessed with validated questions, ${ }^{21}$ and patients who stopped smoking during the study and were not currently using nicotine replacement therapy were asked to provide a saliva sample for measurement of cotinine. The smoking outcome measures were abstinence as verified by measurement of cotinine at 4 and 12 months together with reported number of cigarettes smoked per day. Dietary fat intake was assessed with the dietary instrument for nutritional education. ${ }^{22}$ Physical activity was measured as the number of episodes of vigorous or moderate activity (as defined in the national fitness survey assessment instrument) completed in the past 4 weeks. Stage of change for smoking cessation, dietary fat reduction, and increasing physical activity were assessed with measures described elsewhere. ${ }^{23}$

Statistical comparison of intervention and control groups was carried out with weighted means for each practice thereby taking account of cluster effects. ${ }^{24}$

\section{Results}

\section{Characteristics of the sample}

A total of 316 intervention and 567 control patients were recruited. The patients assigned to the two groups did not differ in age (mean 46.7 (SE 0.4) years), sex distribution (406 men, 477 women), and marital, educational, or employment status. ${ }^{14}$ At baseline 404 participants were smokers ( $45.8 \%$ of the sample), 365 of $871(41.9 \%)$ had cholesterol concentrations in the range $6.5-9.0 \mathrm{mmol} / \mathrm{l}$, and 699 (79.2\% of the sample) had a body mass index in the range 25-35 coupled with insufficient regular physical activity. The proportions of patients with one, two, and three target risk factors were $43 \%, 48 \%$, and $9 \%$ respectively.

\section{Drop out from the study}

Overall, $626(70.9 \%)$ of the 883 patients entering the trial completed the 4 month assessment, and 520 $(58.9 \%)$ were assessed at 12 months (table 1$)$. Failure to complete the trial was not related to sex, education, occupation, or family history of cardiovascular disease. Patients lost to follow up were younger than those who completed the study. They were also more likely to be smokers and less likely to have entered the study on the basis of cholesterol concentration or body mass index and exercise criteria. Participants who smoked and those with a serum cholesterol concentration $<6.5 \mathrm{mmol} / \mathrm{l}$ tended to drop out more in the intervention than control groups at 4 and 12 months. Of the 316 patients in the intervention group, 298 $(90.2 \%)$ attended at least one counselling session, 230 $(72.8 \%)$ attended two, and $176(55.7 \%)$ attended three.

\section{Changes in behaviour and risk factors}

Table 2 summarises the changes in risk behaviour and biological risk factors at 4 months. Greater reductions in dietary fat and the reported number of cigarettes smoked per day, and increases in physical activity, were recorded in the intervention than control groups. However, behaviour changes were not translated into differences in biological risk factors. The only difference was in systolic blood pressure, where the decrease at 4 months was greater in the intervention than control groups. The smoking quit rate was $7.4 \%$ (95\% confidence interval -0.6 to 20.1 ) greater in the intervention than control groups.

Table 3 summarises the results at 4 and 12 months for patients who completed the 12 month assessments. The differences favouring intervention in dietary fat, physical activity, and the number of cigarettes smoked per day were maintained at 12 months. The reduction in systolic blood pressure in the intervention group was also sustained. Total serum cholesterol concentration was reduced to a similar extent in intervention and 
control groups at 12 months. The smoking quit rate at 12 months was $9.4 \%$ ( -9.6 to 28.3 ) greater in the intervention than control groups. There were no differences in response related to age, sex, or number of risk factors. Data related to motivational stage of change will be described elsewhere.

\section{Discussion}

Behavioural counselling by practice nurses for lowering fat intake and increasing physical activity led to changes in target behaviours after 4 months, which were sustained at 12 months. Our study was successful in its primary aim of showing that brief counselling on the basis of the systematic application of behavioural principles is more efficacious in stimulating lifestyle modification than is the conventional counselling and advice provided in general practice. The results for smoking were equivocal, with differences in the number of cigarettes smoked per day but not in smoking quit rates. The smoking results were compromised by the differential drop out of smokers from the intervention group.

\section{Problems of recruitment}

We experienced considerable difficulties in recruitment and retention to this study, and the dropout rate was higher than that found in previous trials in general practice. ${ }^{3}{ }^{4}$ Young smokers were especially likely to default, a pattern reported in other studies of risk factor reduction. ${ }^{25}$ The decline in enthusiasm for primary prevention of coronary heart disease in general practice over recent years may have contributed to this pattern. We hoped to recruit similar numbers in the two arms of the trial, but the control practices recruited nearly twice as many patients. The slower recruitment in the intervention than control groups may have related to the additional investment of time in carrying out behavioural counselling. Additional research staff joined the study to work on site to increase recruitment, and did succeed in increasing rates. Health promotion checks had been carried out in several practices in previous years and these had highlighted cardiac risks. Fewer patients than anticipated were therefore available for assessment. The greater dropout rate for the intervention group may have resulted from its more demanding nature. Recruitment and retention required the commitment of all staff and not only the study nurses, but many health professionals in primary care are ambivalent about advising patients in lifestyle change. ${ }^{26}$

\section{Behaviour and risk factor changes}

The changes in behaviour did not lead to differential reductions in biological risk factors. A similar pattern has been observed in other studies of lifestyle change. ${ }^{27}{ }^{28}$ One possible explanation is that patients showed a reporting bias in recalling the number of cigarettes smoked per day, dietary fat consumption, and physical activity. Although such a bias may have been operative, associations were recorded between changes in behaviour and changes in related biological factors. In addition, biochemical verification of smoking status identified only two cases in which self reported smoking cessation was misreported.
Table 1 Rates of follow up by baseline risk characteristics

\begin{tabular}{|c|c|c|c|c|}
\hline \multirow[b]{2}{*}{ Variables } & \multicolumn{2}{|c|}{4 months } & \multicolumn{2}{|c|}{12 months } \\
\hline & Rate (\%) & $\begin{array}{c}\text { \% difference } \\
\text { (95\% CI) }\end{array}$ & Rate (\%) & $\begin{array}{c}\text { \% difference } \\
\text { (95\% CI) }\end{array}$ \\
\hline \multicolumn{5}{|l|}{ No of patients } \\
\hline Intervention $(\mathrm{n}=316)$ & $204(65)$ & \multirow{2}{*}{$9.9(-1.3$ to 21.0$)$} & $169(54)$ & \multirow{2}{*}{$8.4(-4.7$ to 21.5$)$} \\
\hline Control $(n=567)$ & $422(74)$ & & $351(62)$ & \\
\hline \multicolumn{5}{|l|}{ Cigarette smoking } \\
\hline \multicolumn{5}{|l|}{ Non-smokers: } \\
\hline Intervention $(\mathrm{n}=192)$ & $145(76)$ & \multirow{2}{*}{$6.4(-4.8$ to 17.6$)$} & $129(67)$ & \multirow{2}{*}{$3.5(-10.5$ to 17.6$)$} \\
\hline Control $(n=287)$ & $235(82)$ & & $203(71)$ & \\
\hline \multicolumn{5}{|l|}{ Smokers: } \\
\hline Intervention $(n=124)$ & $59(48)$ & \multirow{2}{*}{$19.2(4.1$ to 34.4$)$} & $40(32)$ & \multirow{2}{*}{20.6 (7.9 to 33.3$)$} \\
\hline Control $(n=280)$ & $187(67)$ & & $148(53)$ & \\
\hline \multicolumn{5}{|c|}{ Cholesterol concentration (mmol/l) } \\
\hline \multicolumn{5}{|l|}{$<6.5:$} \\
\hline Intervention $(\mathrm{n}=161)$ & $89(55)$ & \multirow{2}{*}{$18.1(6.7$ to 29.4$)$} & $68(42)$ & \multirow{2}{*}{15.7 (2.7 to 28.7$)$} \\
\hline Control $(n=345)$ & $253(73)$ & & $200(58)$ & \\
\hline \multicolumn{5}{|l|}{$6.5-9.0:$} \\
\hline Intervention $(\mathrm{n}=153)$ & $115(75)$ & \multirow{2}{*}{$3.6(-8.9$ to 16.2$)$} & $100(65)$ & \multirow{2}{*}{$5.4(-8.5$ to 19.3$)$} \\
\hline Control $(n=212)$ & $167(79)$ & & $150(71)$ & \\
\hline \multicolumn{5}{|c|}{ Body mass index and exercise } \\
\hline \multicolumn{5}{|l|}{$<25:$} \\
\hline Intervention $(\mathrm{n}=64)$ & $36(56.3)$ & \multirow{2}{*}{$9.6(-7.0$ to 26.1$)$} & $33(51.6)$ & \multirow{2}{*}{$0.1(-14.2$ to 14.4$)$} \\
\hline Control $(n=120)$ & $79(65.8)$ & & $62(51.7)$ & \\
\hline \multicolumn{5}{|c|}{ 25-35 with low physical activity: } \\
\hline Intervention $(\mathrm{n}=252)$ & $168(66.7)$ & \multirow{2}{*}{$10.1(-0.8$ to 20.9$)$} & $136(54.0)$ & \multirow{2}{*}{$10.7(-4.3$ to 25.7$)$} \\
\hline Control $(n=447)$ & $343(76.7)$ & & $289(64.7)$ & \\
\hline
\end{tabular}

Positive differences indicate greater proportions of control than intervention patients retained in study.

Table 2 Comparison of changes in risk behaviour and biological risk factors between intervention and control patients at 4 months

\begin{tabular}{|c|c|c|c|c|}
\hline Variable & $\begin{array}{l}\text { Baseline } \\
\text { mean (No) }\end{array}$ & $\begin{array}{c}\text { Change from } \\
\text { baseline }(95 \% \mathrm{CI})\end{array}$ & $\%$ change & $\begin{array}{l}\text { Difference in change } \\
(95 \% \mathrm{CI})\end{array}$ \\
\hline \multicolumn{5}{|c|}{ Cigarettes per day } \\
\hline Intervention & $20.2(59)$ & 6.7 (4.4 to 8.9$)$ & 33.2 & \multirow{2}{*}{$4.5(2.1$ to 7.0$)$} \\
\hline Control & $16.3(184)$ & $2.2(0.8$ to 3.5$)$ & 13.5 & \\
\hline \multicolumn{5}{|l|}{ Fat score* } \\
\hline Intervention & $30.8(186)$ & 8.0 (5.1 to 10.8$)$ & 26.0 & \multirow{2}{*}{$4.8(1.6$ to 8.0$)$} \\
\hline Control & $27.9(386)$ & $3.2(1.3$ to 5.1$)$ & 11.5 & \\
\hline \multicolumn{5}{|c|}{ Exercise (No of sessions) $†$} \\
\hline Intervention & $5.29(199)$ & 7.6 (5.7 to 9.3$)$ & 143 & \multirow{2}{*}{3.7 (1.3 to 6.2$)$} \\
\hline Control & $4.84(420)$ & 3.8 (1.9 to 5.8$)$ & 79.4 & \\
\hline \multicolumn{5}{|c|}{ Body mass index } \\
\hline Intervention & $28.6(204)$ & $0.38(0.1$ to 0.7$)$ & 1.3 & \multirow{2}{*}{$0.15(-0.18$ to 0.48$)$} \\
\hline Control & $28.2(421)$ & $0.23(0.01$ to 0.4$)$ & 0.8 & \\
\hline \multicolumn{5}{|c|}{ Body weight (kg) } \\
\hline Intervention & $80.9(204)$ & $1.0(0.2$ to 1.8$)$ & 1.3 & \multirow{2}{*}{$0.4(-0.5$ to 1.3$)$} \\
\hline Control & $80.2(422)$ & $0.7(0.5$ to 1.2$)$ & 0.8 & \\
\hline \multicolumn{5}{|c|}{ Systolic blood pressure $(\mathrm{mm} \mathrm{Hg}) \ddagger$} \\
\hline Intervention & $135.5(200)$ & $3.3(1.8$ to 4.7$)$ & 2.4 & \multirow{2}{*}{2.4 (0.1 to 4.8$)$} \\
\hline Control & $128.7(409)$ & $0.9(-1.2$ to 3.0$)$ & 0.7 & \\
\hline \multicolumn{5}{|c|}{ Diastolic blood pressure $(\mathrm{mm} \mathrm{Hg}) \ddagger$} \\
\hline Intervention & $82.8(200)$ & $1.9(0.6$ to 3.3$)$ & 2.4 & \multirow{2}{*}{$1.1(-0.6$ to 2.8$)$} \\
\hline Control & $79.7(408)$ & $0.8(-0.4$ to 2.1$)$ & 1.1 & \\
\hline \multicolumn{5}{|c|}{ Smoking prevalence } \\
\hline Intervention & $28.9(204) \S$ & $18.6(0.5$ to 31.9$)$ ฯ & & \multirow{2}{*}{$7.4(-0.6 \text { to } 20.1)^{\star \star}$} \\
\hline Control & $44.3(422) \S$ & $11.2(0.5$ to 17.1$)$ q & & \\
\hline
\end{tabular}

Positive scores indicate favourable changes-for example, reduced body mass index, increased exercise.

${ }^{*}$ Dietary instrument for nutritional education. ${ }^{22}$

†Episodes of vigorous or moderate activity in past 4 weeks.

$\ddagger$ Patients taking antihypertensive drugs excluded.

§Baseline prevalence.

ISmoking quit rate.

${ }^{* *}$ Difference in quit rate

A second possibility is that counselling provided by practice nurses was insufficient to stimulate more substantial changes in behaviour. Contact time totalled 40 and 60 minutes for patients counselled for 
Table 3 Comparison of changes in risk behaviour and biological risk factors between intervention and control patients at 4 months and one year who completed one year assessments

\begin{tabular}{|c|c|c|c|c|c|c|c|c|}
\hline \multirow[b]{2}{*}{ Variable } & \multicolumn{4}{|c|}{4 months } & \multicolumn{4}{|c|}{12 months } \\
\hline & $\begin{array}{l}\text { Baseline } \\
\text { mean (No) }\end{array}$ & $\begin{array}{c}\text { Change from baseline } \\
(95 \% \mathrm{Cl})\end{array}$ & $\%$ change & $\begin{array}{c}\text { Difference in change } \\
(95 \% \mathrm{CI})\end{array}$ & $\begin{array}{l}\text { Baseline mean } \\
(\mathrm{No})\end{array}$ & $\begin{array}{c}\text { Change from baseline } \\
(95 \% \mathrm{Cl})\end{array}$ & $\%$ change & $\begin{array}{l}\text { Difference in change } \\
(95 \% \mathrm{Cl})\end{array}$ \\
\hline \multicolumn{9}{|c|}{ Cigarettes per day } \\
\hline Intervention & $20.9(37)$ & 7.1 (4.8 to 9.4$)$ & 34.0 & \multirow{2}{*}{$5.3(2.9$ to 7.7$)$} & $20.8(40)$ & $8.0(3.7$ to 12.1$)$ & 38.5 & \multirow{2}{*}{$5.2(1.1$ to 9.3$)$} \\
\hline Control & $16.3(129)$ & $1.8(0.6$ to 3.1$)$ & 11.0 & & $15.3(145)$ & 2.7 (1.4 to 4.1$)$ & 17.6 & \\
\hline \multicolumn{9}{|l|}{ Fat score* } \\
\hline Intervention & $30.6(152)$ & $8.3(5.5$ to 11.1$)$ & 27.1 & \multirow{2}{*}{5.7 (2.6 to 8.8$)$} & $30.5(152)$ & 7.1 (4.7 to 9.4$)$ & 23.3 & \multirow{2}{*}{2.8 (0.1 to 5.5$)$} \\
\hline Control & $27.6(319)$ & $2.6(0.8$ to 4.5$)$ & 9.4 & & $28.2(319)$ & $4.3(2.5$ to 6.0$)$ & 15.2 & \\
\hline \multicolumn{9}{|c|}{ Exercise (No of sessions)† } \\
\hline Intervention & $4.9(153)$ & $8.3(6.5$ to 10.1$)$ & 169 & \multirow{2}{*}{4.7 (2.0 to 7.5$)$} & $5.56(167)$ & 8.2 (6.7 to 9.6$)$ & 146 & \multirow{2}{*}{$3.9(1.0$ to 6.8$)$} \\
\hline Control & $5.6(320)$ & 3.6 (1.3 to 5.9$)$ & 64.2 & & $4.82(344)$ & $4.3(1.5$ to 7.1$)$ & 88.8 & \\
\hline \multicolumn{9}{|c|}{ Total serum cholesterol concentration $(\mathrm{mmol} / \mathrm{l}) \ddagger$} \\
\hline Intervention & - & - & - & \multirow[t]{2}{*}{-} & $6.61(164)$ & $0.31(0.21$ to 0.46$)$ & 5.1 & \multirow{2}{*}{$-0.02(-0.21$ to 0.17$)$} \\
\hline Control & - & - & - & & $6.20(334)$ & $0.33(0.15$ to 0.48$)$ & 5.1 & \\
\hline \multicolumn{9}{|c|}{ Body mass index } \\
\hline Intervention & $28.5(153)$ & $0.38(0.1$ to 0.7$)$ & 1.3 & $0.13(-0.18$ to 0.44$)$ & $28.4(168)$ & $0.23(-0.12$ to 0.6$)$ & 0.8 & $0.16(-0.22$ to 0.54$)$ \\
\hline \multicolumn{9}{|c|}{ Body weight (kg) } \\
\hline Intervention & $80.0(153)$ & $1.1(0.5$ to 1.8$)$ & 1.3 & \multirow{2}{*}{$0.6(-0.3$ to 1.4$)$} & $80.3(168)$ & $0.6(-0.4$ to 1.6$)$ & 0.7 & \multirow{2}{*}{$0.4(-0.7$ to 1.5$)$} \\
\hline Control & $79.2(320)$ & $0.6(-0.1$ to 1.2$)$ & 0.7 & & $79.6(350)$ & $0.2(-0.4$ to 0.8$)$ & 0.3 & \\
\hline \multicolumn{9}{|c|}{ Systolic blood pressure $(\mathrm{mm} \mathrm{Hg}) \S$} \\
\hline Intervention & $136.5(153)$ & $3.5(1.4$ to 5.3$)$ & 2.6 & \multirow{2}{*}{$3.2(0.4$ to 6.0$)$} & $135.4(165)$ & $4.3(2.3$ to 7.0$)$ & 3.2 & \multirow{2}{*}{$2.8(-0.3$ to 5.9$)$} \\
\hline Control & $129.0(320)$ & $0.3(-2.0$ to 2.5$)$ & 0.2 & & $128.9(339)$ & $1.8(-0.5$ to 4.1$)$ & 1.4 & \\
\hline \multicolumn{9}{|c|}{ Diastolic blood pressure $(\mathrm{mm} \mathrm{Hg}) \S$} \\
\hline Intervention & $82.8(153)$ & $1.4(-0.1$ to 2.9$)$ & 1.7 & \multirow{2}{*}{$0.7(-1.9$ to 2.7$)$} & $82.4(165)$ & $0.7(-1.6$ to 3.1$)$ & 0.9 & \multirow{2}{*}{$-0.3(-2.6$ to 2.1$)$} \\
\hline Control & $79.5(320)$ & $0.7(0.9$ to 2.2$)$ & 0.9 & & $79.2(338)$ & $1.0(-.01$ to 2.0$)$ & 1.3 & \\
\hline \multicolumn{9}{|c|}{ Smoking prevalence } \\
\hline Intervention & $24.2(153) \emptyset$ & $21.7(3.7 \text { to } 39.5)^{\star *}$ & & \multirow{2}{*}{$12.5(-5.2$ to 30.1$) \mathrm{t \dagger}$} & $23.7(169)$ 川 & $25.0(6.0 \text { to } 44.0)^{\star *}$ & & \multirow{2}{*}{$9.4(-9.6$ to 28.3$) \dagger$} \\
\hline Control & $40.9(320) \emptyset$ & $9.1(2.6 \text { to } 15.7)^{\star \star}$ & & & $42.2(351) \Re$ & $15.6(8.1 \text { to } 23.2)^{\star *}$ & & \\
\hline
\end{tabular}

Positive scores indicate favourable changes-for example, reduced body mass index, increased exercise.

${ }^{*}$ Dietary instrument for nutritional education. ${ }^{22}+$ Episodes of vigorous or moderate activity in past 4 weeks. $\ddagger$ Patients taking lipid lowering drugs excluded.

§Patients taking antihypertensive drugs excluded. १Baseline prevalence. ${ }^{* *}$ Smoking quit rate. $† \dagger$ Difference in quit rate.

one and two risk factors respectively, and part of this time was spent in assessment. Another explanation is that the power of the study was insufficient, particularly for smoking cessation. Because of the difficulties in recruitment, the number of patients (883) fell short of the sample size (2000) on which the initial power calculations were based. ${ }^{14}$

The reduction in total serum cholesterol concentration in the control group was larger than we had anticipated. The general practices in the study had agreed not to prescribe lipid lowering drugs to patients during the course of the trial, and only a small number of instances were reported. It is unlikely that statins were widely prescribed in the light of the uncertainty expressed by general practitioners about their use in primary prevention. ${ }^{29}$ Although the reduction in dietary fat intake was smaller in the control than intervention groups it may nevertheless have been sufficient to stimulate changes in cholesterol of comparable size in the two groups.

\section{Implications for prevention of coronary heart} disease

The primary aim of our study was to evaluate the impact of behavioural counselling by practice nurses on high risk behaviours in patients at increased risk of coronary heart disease. The efficacy of the method has been shown, but given the difficulties of recruitment to this study, the attrition rates, and the low impact of behavioural change on measurable biological risk factors, the implications for service general practice are less clear. More extended counselling may be required to translate behaviour change into measurable reductions in risk. Nevertheless in view of the increasing emphasis on disease prevention within health improvement programmes, and the need for all primary care groups to contribute to these, there may be an important role for this counselling approach to appropriately targeted individuals.

\section{What is already known on this topic}

Health promotion advice and lifestyle counselling in primary care have not produced substantial changes in cardiovascular risk factors

Behavioural counselling for patients at increased risk of coronary heart disease may have greater effects

\section{What this study adds}

Brief behavioural counselling on the basis of the stage of change model led to greater changes in dietary fat intake, regular physical activity, and number of cigarettes smoked than with standard care

More extended counselling and support may be needed to translate sustained changes in health behaviour into improvements in biological risk profile 
The Health Education Authority's primary health care unit in Oxford assisted with modifying the Helping People Change package. Further advice was obtained from Professor Brian Oldenburg (Queensland University of Technology), and Professor Robert West (St George's Hospital Medical School) contributed to the training in smoking cessation.

Contributors: AS and SH devised the original research question and developed the protocol with SD, ER, and TK. SD was responsible for nurse training, quality assurance, and data collection. TK, ER, and SD recruited the general practices, and ER managed contact with participating practices. SK led the work on power calculations and advised on analyses. AS carried out the analyses and wrote the first draft of the paper. AS and $\mathrm{SH}$ will act as guarantors for the paper.

Funding: NHS research and development programme in cardiovascular disease and stroke.

Competing interests: None declared.

1 Kok G, van der Borne B, Dolan Mullen P. Effectiveness of health education and health promotion: meta-analyses of effect sizes and determinants of effectiveness. Pat Educ Couns 1997;30:19-27.

2 Wood D, De Backer G, Faergeman O, Graham I, Mancia G, Pyorala K Prevention of coronary heart disease in clinical practice. Summary of recommendations of the second joint task force of European and other societies on coronary prevention. J Hypertens 1998;16:1407-14.

3 Family Heart Study Group. Randomised controlled trial evaluating cardiovascular screening and intervention in general practice: principal results of the British family heart study. BMJ 1994;308:313-20.

4 Imperial Cancer Research Fund OXCHECK Study Group. Effectiveness of health checks conducted by nurses in primary care: final results of the OXCHECK study. BMJ 1995;310:1099-1104

5 Wonderling D, Langham S, Buxton M, Normand C, McDermott C. What can be concluded from the Oxcheck and British family heart studies: commentary on cost effectiveness analyses. BMJ 1996;312:1274-8.

6 Jackson C. Behavioral science theory and principles for practice in health education. Health Educ Res 1997;12:143-50.

7 Hillsdon M, Thorogood M, Anstiss T, Morris J. Randomised controlled trials of physical activity promotion in free living populations: a review. $J$ Epid Comm Health 1995;49:448-53.

8 Law M, Tang TL. An analysis of the effectiveness of interventions intended to help people stop smoking. Arch Intern Med 1995;155:1933-41.

9 Tang JL, Armitage JM, Lancaster T, Silagy CA, Fowler GH, Neil HAW. Systematic review of dietary intervention trials to lower blood total cholesterol in free-living subjects. BMJ 1998;316:1213-9.

10 Ashworth P. Breakthrough or bandwagon? Are interventions tailored to stage of change more effective than non-staged interventions? Health Educ J 1997;56:166-74.

11 Pierce JP, Farkas AJ, Gilpin EA. Beyond stages of change: the quitting continuum measures progress towards successful smoking cessation. Addiction 1998;93:277-86.
12 Calfas KJ, Long BT, Sallis JF, Wooten W, Pratt M, Patrick KA. A controlled trial of physician counselling to promote the adoption of physical activity. Prev Med 1996;25:225-33.

13 Prochaska JO, DiClemente CC, Norcross JC. In search of how people change. Am Psychol 1992;47:1102-14.

14 Hilton S, Doherty S, Kendrick T, Kerry S, Rink E, Steptoe A. Promotion of healthy behaviour among adults at increased risk of coronary heart disease in general practice: methodology and baseline data from the change of heart study. Health Educ J 1999;58:3-16.

15 Treasure T, MacRae KD. Minimisation: the platinum standard for trials? Randomisation doesn't guarantee similarity of groups; minimisation does. $B M J$ 1998;317:362-3

16 Jarman B. Identification of underprivileged areas. BMJ 1983;286:1705-8.

17 Sports Council and the Health Education Authority. Allied Dunbar national fitness survey. London: Sports Council, 1992.

18 Health Education Authority. Helping people change; health promotion in primary health care. London: HEA, 1994.

19 Hunt P, Hillsdon M. Eating and exercise behaviour: a handbook for professionals. Oxford: Blackwell Science, 1996

20 Silagy C, Mant D, Fowler G, Lancaster T. Nicotine replacement therapy for smoking cessation. In: Cochrane Collaboration. Cochrane Library Issue 3. Oxford: Update Software, 1998.

21 West RJ, Jarvis MJ, Russell MAH, Carruthers ME, Feyerbend C. Effects of nicotine smoking replacement on the cigarette withdrawal syndrome. $B$ J Addict 1984;79:215-9.

22 Roe L, Strong C, Whiteside C, Neil A, Mant D. Dietary interventions in primary care: validity of the DINE method for diet assessment. Fam Pract 1994:11:375-81

23 Doherty S, Steptoe A, Rink E, Kendrick T, Hilton S. Readiness to change health behaviours in patients at high risk for cardiovascular disease. $J$ Card Risk 1998;5:147-53.

24 Bland JM, Kerry SM. Statistics notes: weighted comparison of means. BMJ 1998;316:129

25 McCann TJ, Criqui MH, Kashani IA, Sallis JF, Calfas KJ, Langer RD, et al . A randomized trial of cardiovascular risk factor reduction: patterns of attrition after randomization and during follow-up. J Cardiovasc Rish $1997 ; 4: 41-6$.

26 Johanson M, Satterlund Larsson U, Saljo R, Svardsudd K. Lifestyle discussion in the provision of health care: an empirical study of patientphysician interaction. Soc Sci Med 1998;47:103-12.

27 Cupples ME, McKnight A. Randomised controlled trial of health promotion in general practice for patients at high cardiovascular risk. $B M$ J 1994;309:993-6.

28 Howard-Pitney B, Winkleby MA, Albright CL, Bruce B, Fortmann SP. The Stanford nutrition action program: a dietary fat intervention for low-literacy adults. Am J Publ Health 1997:87:1971-6.

29 Fairhurst K, Huby G. From trial data to practical knowledge: qualitative study of how general practitioners have accessed and used evidence about statin drugs in their management of hypercholesterolaemia. $B M$ $1998 ; 317: 1130-4$

(Accepted 29 July 1999)

\section{Commentary: Treatment allocation by the method of minimisation}

Simon Day

Simple randomisation is the standard method for allocating participants to treatment groups in clinical trials. In the long run it balances all features of participants across groups. Important prognostic factors may be identified at the design stage, and stratified randomisation can help to balance these features. Ensuring a similar proportion of fund holders in the intervention and control groups was, reasonably, considered as important by Steptoe et al, as was balancing for the Jarman score and the ratio of patient to practice nurse hours per week.

Stratified randomisation seems a sensible option and works well when there is just one stratification factor. For example, stratification by fundholding status is simple: there are three randomisation lists, one for non-fundholders and one each for the first wave and second wave. Each must have balanced numbers for each treatment. However, simultaneous stratification for several factors can lead to more randomisation lists than there are participants in the study. With many factors, minimisation is more practical.

Example for allocating the 19th general practice by minimisation

\begin{tabular}{lll}
$\begin{array}{l}\text { Prognostic factor } \\
\text { Jarman score }\end{array}$ & Intervention group & Control group \\
\hline Low* & 4 & \\
\hline Middle & 3 & 3 \\
\hline High & 2 & 5 \\
\hline Patient to practice hours per week & & 1 \\
\hline Low & 4 & 5 \\
\hline High & 5 & 4 \\
\hline Fundholding status & & \\
\hline Non-fundholder* & 3 & 3 \\
\hline 1st wave entry & 4 & 3 \\
\hline 2nd wave entry & 2 & 3
\end{tabular}

${ }^{*}$ Status of next general practitioner to be allocated. 
Minimisation works towards minimising the total imbalance across all factors, rather than any one factor. Assume the first 18 general practices had been randomised and are distributed as in the table. The next general practitioner has a low Jarman score, a high patient to practice nurse ratio "hours per week," and is a non-fundholder. The number of practices of this type in the intervention group is 12-that is, $4+5+3$-and in the control group is 10 -that is,
$3+4+3$. Hence, to minimise the imbalance (even if not to eliminate it) this 19th practice would be allocated to the control group.

Minimisation is possible by hand but a computer program helps when there are many factors or more then two treatment groups. Planning to use minimisation is a good discipline for making trialists think about prognostic factors before a study starts and helps ensure adherence to the protocol as a trial progresses.

\title{
梅
}

\section{Cluster randomised controlled trial of expert system based on the transtheoretical ("stages of change") model for smoking prevention and cessation in schools}

\author{
Paul Aveyard, K K Cheng, Joanne Almond, Emma Sherratt, Robert Lancashire, Terry Lawrence, \\ Carl Griffin, Olga Evans
}

\begin{abstract}
Editorial by Reid
Department of

Public Health and

Epidemiology,

University of

Birmingham,

Birmingham

B15 2TT

Paul Aveyard

lecturer in public

health medicine

K K Cheng

professor of

epidemiology

Joanne Almond

research associate

Emma Sherratt

research fellow

Robert Lancashire

computing officer

Terry Lawrence

senior health

development adviser

Carl Griffin

research associate

Olga Evans

research fellow

Correspondence to:

P Aveyard

p.n.aveyard@bham.

ac.uk
\end{abstract}

BMJ 1999;319:948-53

website

extra

Information on

process

assessment and a

figure showing

flow of participants

are on the BMJ's

website

www.bmj.com

\begin{abstract}
Objectives To examine whether a year long programme based on the transtheoretical model of behaviour change, incorporating three sessions using an expert system computer program and three class lessons, could reduce the prevalence of teenage smoking.

Design Cluster randomised trial comparing the intervention to a control group exposed only to health education as part of the English national curriculum. Setting 52 schools in the West Midlands region. Participants 8352 students in year 9 (age 13-14 years) at those schools.

Main outcome measures Prevalence of teenage smoking 12 months after the start of the intervention. Results Of the 8352 students recruited, 7444 (89.1\%) were followed up at 12 months. The intention to treat odds ratio for smoking in the intervention group relative to control was 1.08 (95\% confidence interval 0.89 to 1.33 ). Sensitivity analysis for loss to follow up and adjustment for potential confounders did not alter these findings.

Conclusions The smoking prevention and cessation intervention based on the transtheoretical model, as delivered in this trial, is ineffective in schoolchildren aged 13-14.
\end{abstract}

\section{Introduction}

Between 1993 and 1996 the percentage of regular smokers among 15 year olds in England increased from $19 \%$ to $28 \%$ in boys and from $26 \%$ to $33 \%$ in girls. ${ }^{1}$ The British government is committed to reducing this. ${ }^{2}$ School programmes are attractive vehicles for this because most schools teach health education as part of personal health and social education. The results of school interventions to prevent smoking have been disappointing, however. ${ }^{3-5}$ Short term reductions in smoking prevalence that were found in some studies disappeared after three years. ${ }^{45}$

The transtheoretical model proposes that people change behaviour by moving through a sequence of stages-"stages of change." ${ }^{7}$ The model describes both how people become smokers and how they stop. Ten psychological processes move people through the stages; some processes are important for movement from one particular stage and not others. The other elements of the transtheoretical model comprise decisional balance (the balance of the pros and cons of smoking), self efficacy (the degree of confidence in oneself to accomplish the change to non-smoking or to remain a non-smoker), and temptations (to smoke). This influential model is incorporated in many health promotion programmes. ${ }^{8}$ The most exciting aspect of the theory is that it leads directly to interventions. Validated questionnaires measure the key elements of the transtheoretical model. ${ }^{9-11}$ An individual can be characterised as being in one particular stage of change. Feedback, together with helpful strategies for increasing confidence, resisting temptation, and thinking about their smoking in the correct way, should help that individual progress to the next stage of change. ${ }^{12}$ This process of diagnosis, feedback, and a stock of helpful strategies for how to move stage have been incorporated into a computer program-an expert system. ${ }^{713}$ An expert system for adults has been tested and was more effective in smoking cessation than stage based manuals alone. ${ }^{15}$ The only published study that used the adolescent system to help school age smokers stop was a feasibility study and was too small to test the efficacy of the intervention. ${ }^{16}$ Here we report a large school based intervention study incorporating the expert system for smoking prevention and cessation in adolescents based on the transtheoretical model.

\section{Method}

\section{Sampling}

We chose school year 9 , with students aged 13-14 years, to participate in the trial. We calculated the intraclass correlation coefficient (0.008) for smoking prevalence for this age group in schools from the West Midlands young people's lifestyle survey. ${ }^{17}$ Using this, the predicted prevalence of smoking in year 10 and the 